\title{
PENELUSURAN SISTEM KEPERCAYAAN SUKU DOHOI (ANAK SUKU OT DANUM) DI TUMBANG SAMBA KABUPATEN KATINGAN KALIMANTAN TENGAH
}

\author{
Fimeir Liadi \\ Institut Agama Islam Negeri (IAIN) Palangka Raya \\ E-mail: fimeirliadi@gmail.com
}

\begin{abstract}
This research started from the desire to do Da'wah Islamiyah to the inland residents of Central Kalimantan, especially to the Dayaks who have the power of Exotic Drag to be studied and dii through the door of their social culture. Actually the belief system is a form of human conquest of humanity to something great, all-powerful and all-great. The Dohoi tribe that is part of the Ot Danak Dayak tribe has a peculiarity in the order of life of his belief, although they have adherence to the Dayak conviction of Kaharingan belief. The Dohoi tribe as adherents of the Helu religion (ancient religion) continue to hold rituals of Kaharingan faith even though they have embraced other religions such as Protestant, Catholic and Moslem. It is interesting to examine in order to express their strong sense of belief and has survived almost 2 centuries of Kaharingan faith development by its adherents in Central Kalimantan. The results showed that the Dohoi tribe is a follower of syncretism in which their beliefs (Kaharingan) are believed to be the dominant religious teachings they use ie Hindu, Buddhist, Christian / Catholic and Moslem.
\end{abstract}

Keywords: Belief, Dohoi Tribe

\begin{abstract}
Abstrak
Penelitian ini berawal dari adanya keinginan untuk melakukan Dakwah Islamiyah kepada warga Pedalaman Kalimantan Tengah, khususnya kepada Warga Dayak yang memiliki daya Tarik eksotis untuk dikaji dan dalami melalui pintu sosial budaya mereka. Sebenarnya system kepercayaan adalah bentuk rasa ketaklukan manusia kepada sesuatu yang maha dahsyat, maha kuasa dan maha segala-galanya. Suku Dohoi yang merupakan bagian dari Suku Dayak Ot Danum memiliki kekhasan dalam tatanan kehidupan kepercayaannya, meskipun mereka memiliki ketaatan terhadap keyakinan Dayak yaitu Keyakinan Kaharingan. Suku Dohoi sebagai penganut Agama Helu (agama kuno) tetap menyelenggarakan ritual-ritual keyakinan Kaharingan meskipun mereka telah memeluk agama lain seperti Kristen Protestan, Katholik dan Islam. Menarik untuk dikaji dalam rangka mengungkapkan rasa keyakinan mereka yang kokoh dan selalu bertahan hingga hampir 2 abad perkembangan keyakinan Kaharingan oleh penganutnya di Kalimantan Tengah. Hasil Penelitian menunjukkan bahwa Suku Dohoi adalah penganut Sinkretisisme dimana dalam keyakinan mereka (Kaharingan) diyakini adanya ajaran agama lain yang dominan mereka pakai yaitu Hindu, Budha, Kristen/Katholik dan Islam.
\end{abstract}

Kata Kunci: Kepercayaan, Suku Dohoi 


\section{PENDAHULUAN}

Kalimantan Tengah didiami setidaknya tiga suku besar, yaitu Ngaju, Ot Danum. Suku Dayak Ngaju mendiami di pesisir Kalimantan Tengah seperti Sungai Kapuas, Sungai Barito, Sungai Kahayan,Sungai Katingan, Sungai Mentaya, Sungai Pembuang, Sungai Arut. Sedangkan Suku Ot Danum mendiami di daerah hulu sungainya, dan populasi yang paling banyak adalah dipehuluan sungai Barito,Katingan, Kapuas, Mahakam dan Kapuas Kalimantan Barat (Kapuas Busang)

Uud Danum, atau sering juga disebut Ot Danum, adalah sebutan untuk kelompok suku Dayak yang berdiam di antara dua sisi pegunungan Schwaner di Kalimantan Barat dan Kalimantan Tengah. Suku ini menyebar di beberapa daerah sekitar dua provinsi tersebut. Suku Uud Danum yang akan dibahas dalam tulisan ini bermukim di Kec. Serawai dan Kec. Ambalau, Kalimantan Barat. Suku Uud Danum merupakan suku mayoritas di dua tempat ini. Memang ada beberapa suku lain, tetapi jumlah mereka tidak banyak dan hidupnya membaur dengan masyarakat Uud Danum.

Uud Danum adalah kelompok suku dayak yang berdiam di daerah hulu sungai (Uud berarti hulu, Danum berarti air). Ada dua sungai yang mengalir di sana, yaitu sungai Melawi (dari Kec. Ambalau) dan sungai Serawai (menuju Kec. Serawai). Suku Uud Danum yang melewati jalur sungai Melawi disebut Dohoi dan yang melewati sungai Serawai disebut Cihie. Bahasa yang digunakan oleh masyarakat uud Danum adalah bahasa Uud Danum.

Jumlah total masyarakat Uud Danum secara pasti belum bisa diberikan dalam tulisan ini karena belum ada pendataan resmi terhadap jumlah mereka. Sebagai perbandingan, jumlah masyarakat Serawai adalah 21.922 jiwa dengan mayoritas umat beragama Katolik. ${ }^{1}$ Berarti masyarakat Uud Danum Serawai sekitar 60\% dari jumlah tersebut.

Suku Dayak Dohoi adalah sub suku Dayak Rumpun Ot Danum yang bermukim di perbatasan Kalimantan Barat dan Kalimantan Tengah. Di Kabupaten Sintang suku Dohoi berjumlah 14.511 jiwa (tahun 2012). Suku Dohoi menggunakan bahasa Dohoi yang termasuk rumpun bahasa Barito.

Mata pencaharian orang Dohoi adalah bercocok tanam di ladang. Mereka biasanya menumbuk padi pada malam hari, setelah seharian bekerja diladang. Suara tumbukan bertalu-talu ini disambut dengan gelak tawa di setiap hampir rumah tangga. Inilah keunikan suku Dohoi. Hasil panen disimpan pada tempat khusus yang disebut jorong, yaitu rumah yang terbuat dari satu tiang guna menghindari tikus.

${ }^{1}$ BPS Kabupaten Sintang tahun 2010 
Rumah mereka berbentuk persegi panjang dan didirikan 2 - $5 \mathrm{~m}$ di atas tanah dengan tiang-tiang kayu (rumah panggung) dengan tangga bertingkat. Anjing, babi, dan ayam merupakan hewan peliharaan mereka. Mereka juga memelihara sapi untuk disembelih pada perayaan-perayaan besar.

Orang Dohoi juga terkenal dalam kerajinan topi, keranjang, dan berburu juga mereka buat secara lokal. Tanah di sekeliling setiap desa (sekitar 2 - $3 \mathrm{~km}$ jauhnya) dianggap sebagai tanah milik desa. Setiap penduduk desa berhak menjual tanahnya bila dikehendaki, tetapi hanya kepada sesama penduduk desa. Tanah yang tetap kosong selama lebih dari 5 tahun bisa dimiliki oleh siapa saja di desa itu.

Pernikahan di antara saudara sepupu lebih disukai di antara suku Dohoi. Bila telah tercapai persetujuan/kesepakatan oleh orang tua pasangan, keluarga mempelai laki-laki memberikan hadiah secara simbolis kepada keluarga mempelai wanita. Pemberian kedua diberikan ketika pertunangan diumumkan. Sesudah pernikahan dilangsungkan, dilakukan pembayaran kepada pengantin wanita.

Suku Dohoi, saat ini tersebar di Kalimantan Tengah diantaranya di Kecamatan Tumbang Samba Kabupaten Katingan diperkirakan ada 20 sampai 35 keluarga berdiam di pinggiran sungai Katingan.

Kepercayaan yang dianut oleh suatu suku Dohoi dapat ditelusuri melalui ekspresi budaya seperti cerita rakyat, terutama dalam cerita yang berbentuk mitos tentang kejadian alam semesta dan manusia serta mitosmitos lainnya yang menggambarkan keterkaitan yang hakiki antara insan manusia dan alam sekitarnya ${ }^{2}$. Hal yang sama juga dikatakan oleh Ukur, bahwa untuk memahami makna religi dari alam sekitar dalam kebudayaan Dayak, sumber yang paling dapat membantu terutama mite-mite tentang kejadian alam semesta dan manusia serta mite-mite lainnya yang menggambarkan keterikatan dan keterkaitan hakiki antar insan dengan alam sekitar ${ }^{3}$. Dalam tulisan Syahdan, mengemukakan bahwa agama merupakan penjelmaan dari sistem budaya bahkan agama Islam pun dianggap sebagai penjelmaan dari sistem budaya, ${ }^{4}$ sehingga ketika membahas tentang makna religi, maka tentu dapat dikaji melalui budaya orang Dayak.

Mitos bukanlah sekedar cerita, tetapi melalui mitos yang hidup dalam masyarakat Dayak dapat diungkap rahasia yang mendasari dan melatarbelakangi sikap serta perilaku suku Dayak. Keberadaan mitos diyakini kebenarannya, dianggap suci, mengandung hal-hal ajaib, dan umumnya

2 Musni Umberan, Wujud, Arti Dan Fungsi Puncak-Puncak Kebudayaan Lama Dan Asli Di Kalimantan Barat, Pontianak: Proyek Pengkajian Dan Pembinaan Nilai-Nilai Budaya Daerah (Pontianak: Depdikbud Propinsi Kalimantan Barat, 1994).

${ }^{3}$ Frodlin Ukur, Tantang Djawab Suku Dayak (Jakarta: Gunung Mulia, 1971).

${ }^{4}$ Syahdan Syahdan, "Ziarah Perspektif Kajian Budaya (Studi Pada Situs Makam Mbah Priuk Jakarta Utara )," Jurnal Studi Agama dan Masyarakat 13, no. 1 (June 20, 2017): 65-99. 
ditokohi oleh para dewa, sebab itu mitos dijadikan landasan untuk menata kehidupan masyarakat Dayak yang tampak pada berbagai ketentuan seperti adat, ritus dan kultus. Mitos dihayati sebagai sejarah oleh masyarakat Dayak meskipun peristiwa-peristiwa yang dituturkan dalam mitos tidak terikat pada waktu dan ruang. Sejarah dalam konteks pemahaman suku Dayak terhadap mitos tersebut tidak dapat diverifikasi secara historis, menurut Ukur, mitos dianggap sebagai sejarah karena memang ini yang dihayati oleh insan Dayak. ${ }^{5}$

Kepercayaan suku Dayak berhubungan erat dengan lingkungan sekitarnya, seperti hewan, tumbuhan-tumbuhan, air, bumi, dan udara. Kepercayaan itu begitu kuat sehingga suku Dayak percaya bahwa kehidupan akan menjadi baik jika adanya keseimbangan kosmos, sebab itu setiap makhluk hidup berkewajiban untuk senantiasa memelihara keserasian dan keseimbangan semesta, terutama manusia menurut kepercayaan suku Dayak merupakan bagian yang integral dari alam. Sistem kepercayaan dan nilai-nilai budaya yang dimiliki oleh suku Dayak berkaitan erat sehingga sulit untuk dipisahkan. Kedua hal tersebut sama-sama berpengaruh pada kehidupan masyarakat Dayak. ${ }^{6}$

Senada dengan pendapat Seli, Alqadrie juga menyatakan bahwa sistem kepercayaan atau agama bagi kelompok etnik Dayak hampir tidak dapat dipisahkan dengan nilai-nilai budaya dan kehidupan sosial ekonomi mereka sehari-hari. Ini berlaku pula antara nilai-nilai budaya itu dengan etnisitas dalam masyarakat Dayak. Kenyataan ini yang melatar belakangi kesimpulan Coomans dan Alqadrie yang menyatakan bahwa keperipadian, tingkah laku, sikap, perbuatan, dan kegiatan sosial ekonomi orang Dayak sehari-hari dibimbing, didukung oleh dan dihubungkan tidak saja dengan sistem kepercayaan atau ajaran agama dan adat-istiadat atau hukum adat, tetapi juga dengan nilai budaya dan etnisitas. ${ }^{7}$

Kepercayaan atau keyakinan itu direpresentasaikan lewat sikap dan tingkah laku manusia baik melalui tindakan maupun ucapan, hal ini dikarenakan adanya rasa takluk dari sesuatu yang maha dahsyat dan maha besar yang bisa merubah sikap, merubah hidup serta kematian.

Kepercayaan Suku Dohoi tidak lepas dengan apa yang mereka anut sebagai sebuah keyakinan. Mayoritas suku Dohoi menganut agama helu atau Kaharingan. Sebagai sebuah keyakinan Agama Kaharingan memiliki ritual sebagai tindakan dan ucapan sebagai sarana merepresentasikan keyakinan yang mereka jalankan sehari-hari, misalnya sebelum mereka berangkat untuk mencari nafkah, mereka melakukan ritual dan ucapan/mantra sebagai bentuk

\footnotetext{
5 Ukur, Tantang Djawab Suku Dayak.

${ }^{6}$ Seselia Seli, "Struktur, Fungsi, Dan Nilai Budaya Dalam Cerita Rakyat Dayak Kanayant Kabupaten Pontianak" (Program Pascasarjana IKIP, 1996).

${ }^{7}$ Syarif Alqadrie, "Ethnicity and Social Change in Dayaknese Society of West Kalimantan, Indonesia” (Departement of Sociology, University of Kentucky, 1990).
} 
permohonan agar mereka selamat dan bisa memperoleh hasil.Demikian pula setelah dating berusaha mereka mengucapkan rasa syukurnya kepada Maha Pengatur.

Mantra/doa serta ritual itu mereka refresentasikan sebagai bentuk ketidak berdayaan mereka terhadap suatu kekuatan yang maha besar sebagai pandangan hidup mereka.

Bagaimana bentuk system kepercayaan ini dan bagaimana merepresentasikannya dalam kehidupan sehari-hari, menjadi hal yang menarik untuk diteliti, guna memperoleh gambaran konkrit bagaimana Suku Dohoi menjalankan prosesi kepercayaannya melalui bahasa, tentunya dengan bahasanya sendiri yaitu Bahasa Dohoi, melalui kajian bahasa, budaya dan kepercayaan.

\section{TENTANG SUKU DOHOI ANAK SUKU OT DANUM}

Pembagian kelompok suku Dayak di Kalimantan berdasarkan pada kesamaan hukum adat, bahasa, ritus kematian, jalur sungai, maupun kriteria lain, membuktikan adanya keragaman yang alami dan perbedaan yang natural dari pribumi asli pulau ini. Menurut Widjono, terdapat karakteristik yang sifatnya khas yang memperlihatkan kesamaan kebudayaan di antara semua suku Dayak di Kalimantan yang berbeda hanyalah istilah lokalnya saja. Riwut dan Ukur, berdasarkan hasil temuannya mengatakan bahwa ciri pokok kebudayaan Dayak meliputi: (1) rumah panjang; (2) senjata khas; (3) anyamanyaman; (4) tembikar; (5) sistem perladangan; (6) kedudukan perempuan dalam masyarakat; (7) seni tari. ${ }^{8}$

Di masa lalu Suku Dohoi terkenal temperamental, logas, tohpas hohot, dan nyolung osak dahak ah. Logas berarti "mudah naik darah", tohpas lohot berarti "tidak ragu-ragu kalau mengambil keputusan untuk membunuh", dan nyolung osak dahak berarti "orang yang tidak mengenal rasa takut sedikit pun". Pada masa lalu suku Dayak Dohoi memiliki perilaku sangat keras. Mereka punya prinsip, sekali ahpang yaitu "mandau terhunus", maka pantang disarungkan sebelum minum darah manusia. Karena wataknya itulah maka oleh Suku Dohoi lainnya yang berada di sekitar daerah itu menamakan mereka sebagai Dohoi, untuk menyatakan bahwa "mereka ini adalah orang yang logas, tohpas lohot, dan nyolung osak dahak ah".

Suku Dohoi kadang disebut juga sebagai suku Ot Danum. Istilah "ot danum" memiliki arti "orang-orang yang tinggal di wilayah di sepanjang sungai". Pemukiman mereka membentang dari sungai Melawi sampai sungai Barito. Pemukiman mereka terletak di daerah terpencil di pedalaman,

${ }^{8}$ Roedy Haryo Widjono A. M. Z, Masyarakat Dayak menatap hari esok (Penerbit PT Gramedia Widiasarana Indonesia bekerja sama dengan Lembaga Bina Benua Putji Jaji-LPPSKWI, 1998). 
sehingga untuk mencapai pemukiman suku Dohoi ini bisa memakan waktu berhari-hari dengan menggunakan perahu melalui sungai Lamandau.

Suku Dayak Dohoi adalah anak suku Dayak Ot Danum yang ke 52 dari 62 suku kecil berdasarkan urutan anak suku Ot Danum oleh Cilik Riwut sebagai berikut

Tabel 1

\begin{tabular}{|c|c|c|c|c|c|c|}
\hline $\begin{array}{l}\text { Suku } \\
\text { Besar }\end{array}$ & No & Anak Suku & No & Anak Suku & No & Anak Suku \\
\hline Ot & 1 & Lebang & 23 & Kanyilu & 43 & Suku Palin \\
\hline \multirow[t]{23}{*}{ Danum } & 2 & Undan & 24 & Nyadum & 44 & Suku Embaloh \\
\hline & 3 & (Sekarang & 25 & Iban & 45 & Suku Lauk \\
\hline & & rumpun Iban) & 26 & Tahin & 46 & Suku Kalis \\
\hline & 4 & Seberuang (Iban) & 27 & Kubin & 47 & Suku Leboyan \\
\hline & 5 & Payak & 28 & Pangin & 48 & Suku Sebaung \\
\hline & 6 & Linuh & 29 & Pananyui & 48 & Suku Tawahui \\
\hline & 7 & Palan & 30 & Ellah & 50 & Suku Rahan \\
\hline & 8 & Pandu & 31 & Kabahanuku & 51 & Suku Pananyari \\
\hline & 9 & Parai & 32 & Kaninjai & 52 & Suku Dohoi \\
\hline & 10 & Muntok & 33 & Tabidah & 53 & Suku Ot Banusu \\
\hline & 11 & Silang & 34 & Gunih & 54 & Suku Tohup \\
\hline & 12 & Jungkau & 35 & Jampal & 55 & Suku Ot Siang \\
\hline & 13 & Latiyur & 36 & Kayan & 56 & Suku Kalang \\
\hline & 14 & Ot Danun & 37 & Banga & 57 & Lupu \\
\hline & & Danum/kalbar) & 38 & Ulun Daan & & Jambung \\
\hline & 15 & Penang Kuwi & 39 & Mentebah & 58 & Jama \\
\hline & 16 & Nyangoi & 40 & TamanDanun & & Suku Gunung \\
\hline & 17 & Osa & & (sekr.rumpun & 59 & Kambang \\
\hline & 18 & Bunyau & & Banuaka) & & Suku Nyaring \\
\hline & 19 & Sahiei & 41 & Taman Siba & 60 & Uhing \\
\hline & 20 & Serawai Danun & & (sekr.rumpun & & Suku Babuat \\
\hline & 21 & Limbei & & Banuaka) & 61 & Suku Karamai \\
\hline & 22 & Ransa & 42 & $\begin{array}{l}\text { Suku Mandai } \\
\text { Suruk }\end{array}$ & 62 & Suku Kutai \\
\hline
\end{tabular}

Orang Dohoi sebagian besar adalah penganut animisme (percaya bahwa setiap benda memiliki roh) dan polytheisme (menyembah banyak dewa). Tapi pada dasarnya praktek keagamaan mereka berkisar di antara dua dewa, yang satu dilambangkan dengan Burung Enggang dan Ular air.

Upacara-upacara keagamaan bisa berupa acara-acara sederhana maupun pesta-pesta yang lama. Penduduk meminta bantuan Shaman (dukun) untuk mengobati penyakit mereka, yang dalam prakteknya seringkali kerasukan.

Bahasa Dohoi Uud Danum adalah sebuah bahasa yang agak berbeda dari bahasa sub suku Dayak lainnya di luar komunitas mereka. Selain mempunyai tingkatan dalam penggunaan pilihan kosakatanya, bahasa ini juga mempunyai pilihan kosakata dalam bahasa sastranya. Hal ini bisa dilihat jelas dalam bahasa kandan tahtum, dan parung. Menurut para tetua, derajat 
tertunggi bahasa Dohoi Uud Danum adalah dalam bahasa kandan kemudian secara berturut-turut diikuti oleh bahasa tahtum, parung, kendau, dan bahasa sehari-hari.

Suku Dohoi menggunakan bahasa Dohoi yang termasuk rumpun bahasa Barito. Penutur Bahasa Dohoi hanya pada komunitas warga Dohoi. Bahasa ini belum mampu menjadi bahasa pasar "bahasa pasar adalah bahasa yang mudah dimengerti dan dipahami oleh warga lain sebagai bahasa komunikasi keseharian". Hal ini dikarenakan penutur bahasa Dohoi hanya pada komunitasnya. Suku Dohoi dalam berkomunikasi diluar komunitasnya menggunakan bahasa Ngaju atau bahasa Bakumpai sebagai bahasa pengantar keseharian. Oleh sebab itu Bahasa Dohoi dikhawatirkan akan punah seiring dengan pembauran dengan komunitas lain seperti Banjar, Ngaju dan Bakumpai. Dan ini yang dikhawatirkan oleh Prof Lambut bahwa setiap tahun bahasa daerah terdegradasi 20 sampai $30 \%$ pertahunnya, sehingga tdk menutup kemungkinan bahasa local terancam punah karena prilaku penuturnya yang tidak mampu mempertahankan bahasanya seiring terbukanya budaya globalisasi. ${ }^{9}$

Suku Dohoi juga memiliki bahasa mantra disebut Bahasa kandan (bahasa Sangen / mantra /Ngaju) dan bahasa ini dikatakan mempuyai derajat tertinggi, karena apabila orang mau mempelajari bahasa ini maka ia harus melakukan nasih, yaitu memberikan beberapa persyaratan adat kepada orang yang akan mengajarinya, berupa beberapa ketentuan untuk membayar ketentuan adat, membunuh ayam atau babi, memberikan besi sebagai penguat semangat, memberikan sirou sahkik (dalam wujud gelang batu semi mulia), dan sedikit pesta. Sewaktu orang yang belajar bahasa ini sudah menamatkan pelajaran kandan-nya, maka akan diadakan semacam pesta untuk merayakannya. Bahasa kandan ini.

Bahasa Kandaan dipergunakan untuk menceritakan legenda tertua yang disebut Kolimoi, untuk mengobati, untuk bercakap, untuk mohpas, dan apa saja sesuai kebtuhan masing-masing orang. Namun selain itu, bahasa kandan biasa juga digunakan untuk bahasa pengobatan khusus dalam episode nimang pada ritus nyakai. Nyakai ini adalah ritus tertinggi di dalam upacara pengobatan. Ritus awal adalah nyandah, yang kedua adalah hobolian, dan yang terakhir dan tertinggi adalah nyakai tadi.

\section{System Kepercayaan Suku Dohoi}

Kepercayaan suku Dayak, sejak zaman dahulu telah memeluk agama Kaharingan sebagai agama asli sebagian besar suku-suku dayak di Kalimantan. Saat ini sebagian besar masyarakat suku Dayak tetap mempertahankan agama

${ }^{9}$ Fimeir Liadi, Refresentasi Nilai Suku Dayak Ngaju Dalam Manalatai Lewun Sansana, Banjarmasin (Banjarmasin: Borneo Pustaka, 2010). 
Kaharingan, sedangkan sebagian lain telah memeluk agama Kristen dan juga agama Islam. Tetapi walaupun sebagian dari suku Dayak telah memeluk agama Kristen dan Islam, beberapa tradisi Kaharingan masih mereka laksanakan, seperti upacara Tiwah yang terkenal di kalangan masyarakat dayak di Kalimantan Tengah.

Suku Dayak di Kalimantan memiliki sistem kepercayaan yang kompleks dan sangat berkembang. Kompleksitas sistem kepercayaan tersebut di dasarkan pada tradisi dalam masyarakat Dayak yang mengandung dua prinsip yaitu: (1) unsur kepercayaan nenek moyang (ancestral belief) yang meneknkan pada pemujaan nenek moyang, dan (2) kepercayaan terhadap Tuhan yang satu (the one God) dengan kekuasaan tertinggi dan merupkan suatu prima causa dari kehidupan manusia. ${ }^{10}$

Konsepsi Keyakinan atau kepercayaan asli suku Dayak ialah agama Helu atau Kaharingan, yang berasal dari kata haring, artinya hidup. Kaharingan tidak dimulai sejak zaman tertentu, Kaharingan telah ada sejak awal penciptaan, "sejak awal Ranying1) Hatalla") menciptakan manusia. Riwut menjelaskan, Kaharingan ada sejak adanya kehidupan, dan Tuhan mereka adalah Ranying Hatalla telah mengatur segala sesuatunya nuntuk menuju jalan kehidupan kearah kesempurnaan yang kekal abadi. ${ }^{11}$

Menurut pandangan Suku Dohoi, manusia hidup di dunia hanya sementara dialam bawah (dunia) yang disebut dengan Pantai Danum Kalunen $^{3}$, dan akan kembali lagi kealam asalnya yaitu alam atas atau Lewu Liau $^{4}$ atau disebut juga Lewu Tatau Dia Rumping Tulang, Randung Raja Isen Kamalasu $^{5}$. Jadi, konsep ketuhanan orang Dohoi adalah sang Maha Tunggal, Maha Agung, Maha Mulia, Maha Jujur, Maha Lurus, Maha Kuasa, Maha Suci, Maha Pengasih dan Penyayang Maha Adil, Kekal Abadi, Maha Mendengar, yang mempunyai kekuatan dan kekuasaan untuk memberikan kehidupan kepada manusia ia adalah Ranying, yang mempunyai kekuatan untuk mencipta (Hatalla). ${ }^{12}$

Alam adalah ciptaan diperuntukan kepada manusia dalam rangka mencukupi kehidupan dan kesejahteraan manusia sendiri. Pandangan Dayak, "alam adalah anugerah yang sangat besar oleh Ranying Hatalla, ia diciptakan dan jelmaan roh-roh para leluhur yang memiliki daya magis dan penjaganya.

Menurut penjelasan Riwut, dalam membuka lahan, Suku Dayak tidak bisa sembarangan, mereka mohon izin dan memberikan pengganti kerusakan dengan memberikan sesajen kepada penjaga tempat yang mereka buka. Indonesia."

${ }^{10}$ Alqadrie, "Ethnicity and Social Change in Dayaknese Society of West Kalimantan,

11 Tjilik Riwut, Kalimantan Memanggil (Jakarta: Endang, 1958).

12 Riwut, 478. 
Suku Dohoi Ngaju memahami bahwa alam yang telah mereka buka harus diganti dengan tumbuhan lain yang dianggap bermanfaat. Oleh sebab itu, setelah mereka membuka lahan untuk berladang, mereka menanam kembali tumbuhan berupa buah-buahan, seperti duhian, baliti, uei, pinang dan lain-lain.

Membuka lahan hanya secukupnya berdasarkan kemampuan dan kebutuhan mereka sehingga tidak terjadi eksploitasi yang berlebihan. Mereka meyakini bahwa apabila alam digarap secara berlebihan akan membawa mala petaka sebab roh tumbuh-tumbuhan dan penjaganya jadi marah dan itu akan membawa malapetaka bagi kehidupan mereka.

Konsepsi Tatanan Sosial menurut pandangan Suku Dohoi, manusia sempurna adalah manusia yang dapat dan mampu melaksanakan hukum adat dengan sempuna serta mentaati ketentuan Ranying Hatalla. Untuk itu, diaturlah tata krama kehidupan bermasyarakat yang diatur dalam hukum adat.

Tata krama sosial di lingkungan kehidupan masyarakat Suku Dohoi diatur oleh lembaga Dayak yang disebut dengan Kepala Adat atau Demang atau demong atau Mantir Puluhan. Lembaga Adat ini tidak mempunyai wewenang dalam memutuskan perkara melainkan diputuskan dalam sidang/musyawarah Kerapatan Adat, yang terdiri atas beberapa kepala suku, tabakas Lewu dibantu oleh Damang. Tempat musyawarah dan upacara adat dinamakan Balai Basarah.

Pendatang ataupun tamu diharuskan untuk mentaati adat dan jangan sampai melanggar pali, seperti mencuri, merampas dan melecehkan anak gadis dan isteri orang, menghina dan lain-lain. Tamu sangat dihormati oleh warga Dayak. Oleh sebab itu, hendaknya pendatang/tamu diharapkan juga menghormati tata krama adat mereka.

Suku Dohoi sangat menghormati dan menghargai para tetua yang mereka sebut dengan bue, mina mama. Segala sesuatu masalah yang timbul, harus didengar pendapat bue dan mina mama..

\section{Representasi Bahasa Dohoi dalam Kepercayaan Suku Dohoi}

Teori representasi Stuart Hall memperlihatkan suatu proses di mana arti (meaning) diproduksi dengan menggunakan bahasa (language) dan dipertukarkan oleh antar anggota kelompok dalam sebuah kebudayaan (culture). Representasi menghubungkan antara konsep (concept) dalam benak kita dengan menggunakan bahasa yang memungkinkan kita untuk mengartikan benda, orang, kejadian yang nyata ( $r e a l$ ), dan dunia imajinasi dari objek, orang, benda, dan kejadian yang tidak nyata (fictional). ${ }^{13}$

13 Stuart Hall, Representation: Cultural Representation and Signifying Practises (London: Sage, 1997), 17. 
Terdapat tiga definisi dari kata "represent" yakni:

1. To stand in for. Hal ini dapat dicontohkan dalam peristiwa bendera suatu negara, yang jika dikibarkan dalam suatu event olahraga, maka bendera tersebut menandakan keberadaan negara yang bersangkutan dalam event tersebut.

2. To speak or act on behalf of. Contohnya adalah Pemimpin menjadi orang yang berbicara dan bertindak atas nama rakyatnya.

3. To re-present. Dalam arti ini, misalnya tulisan sejarah atau biografi yang dapat menghadirkan kembali kejadian-kejadian di masa lalu. ${ }^{14}$

Praktiknya, ketiga makna dari representasi ini bisa menjadi saling tumpang tindih. Teori yang dikemukakan oleh Hall sangat membantu dalam memahami lebih lanjut mengenai apa makna dari representasi dan bagaimana caranya beroperasi dalam masyarakat budaya.

Teori representasi seperti memakai pendekatan konstruksionis, yang berpendapat bahwa makna dikonstruksi melalui bahasa. Stuart Hall dalam artikelnya, "thigs dont' mean: we construct meaning, using representational system-concept and signs. 15 Oleh karena itu konsep dalam (pikiran) dan tanda (bahasa) menjadi bagian penting yang digunakan dalam proses konstruksi atau produksi makna. Sehingga dapat disimpulkan bahwa representasi adalah suatu proses untuk memproduksi makna dari konsep yang ada dipikiran kita melalui bahasa. Proses produksi makna tersebut dimungkinkan dengan hadirnya sistem representasi. Namun, proses pemaknaan tersebut tergantung pada latar belakang pengetahuan dan pemahaman suatu kelompok sosial terhadap suatu tanda. Suatu kelompok harus memiliki pengalaman yang sama untuk dapat memaknai sesuatu dengan cara yang nyaris sama.

Representasi Kepercayaan Suku Dohoi dalam penelitian ini adalah mereferen dan citraan dari tanda atau bahasa keseharian mereka yang dimaknai sebagai ketundukan atau kepatuhan mereka terhadap apa yang mereka anut (kepercayaan). Untuk itu konsep keyakinan mereka yang disebut dengan Kaharingan dengan segala aturan dari keyakinan itu (prosesi) mereka taati dengan baik, dengan harapan ada pengaruh baik dan menghindari pengaruh yang tidak baik (jahat)

Bentuk rasa tunduk itu, Suku Dohoi melakukan prosesi adat sejak kelahiran sampai kematian dan menggunakan bahasa Dohoi atau Kandan/mantra. Aturan yang mereka pakai adalah aturan Adat Kaharingan yang ada dalam Kitab Panaturanyang diterbitkan oleh Pengurus Besar Dayak Kaharingan Kalimantan Tengah

14 Judy Giles and Tim Middleton, Studying Culture: A Practical Introduction, 2 edition (Malden, MA: Wiley-Blackwell, 2008).

15 Hall, Representation : Cultural Representation and Signifying Practises. 


\section{KONSEPSI KEPERCAYAAN SUKU DOHOI}

a. Konsepsi Ketuhanan

Suku Dohoi adalah penganut agama Kaharingan atau agama Helu. Menurut pandangan Suku Dohoi Tuhan mereka adalah sebagaimana Tuhan Orang Dayak di Kalimantan yaitu "Nyaring Hatala Langit" dan Kitab Sucinya adalah Panaturan sebagaimana diungkapkan oleh Bapak Juang K.Djakat Demang Adat Dayak Kecamatan Sanaman Mantikei yang ditemui Peneliti di Tumbang Samba Kecamatan Katingan Tengah.

"Agama uluh Dohoi adalah "Kaharingan" dan Tuhan mereka adalah "Nyaring Hatala Langit" sebagaimana Tuhan orang Dayak Kalimantan". ${ }^{16}$

Menjalankan ibadah keagamaannya warga Dohoi dipimpin oleh Basir (Pendeta) setiap malam Kamis di Balai Basarah dengan melakukan ritual berpedoman pada buku "Kandayu" buku Penuntun Persembahyangan yang disusun oleh Drs.Rangkap I,Nau,MM Ketua Umum Majelis Besar Agama Hindu Kaharingan Pusat Palangkaraya periode 1993-2001. "Kandayu” adalah buku Penuntun Persembahyangan berbahasa Ngaju. Menurut Bapak Juang K.Djakat, sampai saat ini Suku Dohoi tetap menggunakan buku ini meskipun dalam Bahasa Ngaju, tidak dalam bahasa Dohoi, karena orang Dohoi paham dan mengerti bahasa Ngaju.

Sangat menarik menurut Pak Juang K.Djakat, Bahasa Dohoi adalah bahasa tertua di Kalimantan sehingga mereka bisa paham bahasa lain, seperti Bahasa Klorih atau Kedorih, Bahasa Ngaju asal satu rumpun dalam Suku Ot Danum. Oleh sebab itu prosesi ibadah seperti doa mereka menggunakan bahasa Ngaju dan sedikit menggunakan bahasa Dohoi.

Fakta terakhir, warga Dohoi sudah banyak pindah agama, dan paling banyak ke Agama Katholik dan Kristen Protestan sebagian kecil ke Agama Islam.

"Misioneris Katholik pansulak ah tame kan ngaju sungei perbatasan Kalbar, Kalteng, Kaltim, gawin misioneris jikau manyebar agama ewen (Katholik) manenga Susu, vitamin, obat bahkan ewen mangajar anak uluhan, bakas hatue bawi".17

Paparan di atas dan beberapa nara sumber menyatakan Warga Dohoi masih mayoritas menganut agama Kaharingan dan Tuhan mereka adalah "Ranying Hatala Langit". Agama Katholik dan Agama Kristen adalah agama dengan jumlah populasi kedua dan sangat sedikit warga Dohoi yang masuk Islam.

${ }^{16}$ wawancara Bapak Juang K. Djakat, tanggal,22 Juli 2017 di Tumbang Samba

17 wawancara dengan Bapak Mursid, Tokoh Warga Dohoi Tumbang Pangu Desa Kecamatan Tasik Payawan, Tokoh ini sudah Muslim sejak tahun 1959 dan masuk Islam sekeluarga karena dakwah Islam oleh orang Bakumpai di Desa Tumbang Pangu. tanggal 23 Juli 2017 
b. Konsepsi Alam dan Lingkungan

Alam dan lingkungan bagi warga Dohoi adalah unsur utama dalam mereka menata kehidupannya. Diyakini oleh warga Dohoi bahwa alam dan lingkungan adalah milik sang maha pencipta "Ranying Hatala Langit" yang di kuasakan kepada Duwata untuk menjaga dan merawatnya.

Alam adalah kehidupan mereka dan Suku Dohoi membuat aturan yang disebut dengan jipen bagi orang perusak alam. Jipen adalah denda yang harus diserahkan kepada wali adat sebagai pengganti kesalahan.Jipen bisa diganti dengan binatang ternak dan uang sesuai jumlah jipen yg mereka dakwakan

Ungkapan Ibu Powili seorang ibu warga Dohoi Desa Tukan Kecamatan Petak Malai, dalam merawat alam dan memanfaatkan alam sebagai lumbung kehidupan beliau memberikan saji atau sajen sebelum memulai aktivitas kehutan "Malan mimbul parei, imbul gita, uwei sapuna gowin ulun Dohoi, pas te tinai mandup (berburu) bawui, bajang, mamuei madu, menyon baui, monuk penda pasha, jiko puno menyon Duwata, jo pasi ko nengo kan Duwata ruku, simpa, kopi, nyamo iko jo mamih kanjoru"

(Bertani, menanam padi, menanam karet, menanam rotan adalah pekerjaan orang Dohoi, seperti berburu babi, rusa, memetik madu, memelihara babi, ayam di bawah rumah.Semuanya itu adalah milik Duwata dan harus memberi sesaji pada Duwata rokok, sirih pinang, kopi agar dia tidak marah/Translet Bahasa Dohoi,oleh Wiwinson) Berikutnya kata beliau "Mun ikei palus kan himba manggau rajaki mandup, mamuei atau maneweng pun kayu, pasti permisi helun rima kan ji manjaga kau, mikeh tulah buah papa) ${ }^{18}$.

c. Konsepsi Tatanan Sosial

Konsepsi Tatanan Sosial menurut pandangan Suku Dohoi, manusia sempurna adalah manusia yang dapat dan mampu melaksanakan hukum adat dengan sempuna serta mentaati ketentuan Ranying Hatalla. Untuk itu, diaturlah tata krama kehidupan bermasyarakat yang diatur dalam hukum adat.

Tata krama sosial di lingkungan kehidupan masyarakat Suku Dohoi diatur oleh lembaga Dayak yang disebut dengan Kepala Adat atau Demang atau demong atau Mantir Puluhan. Lembaga Adat ini tidak mempunyai wewenang dalam memutuskan perkara melainkan diputuskan dalam sidang/musyawarah Kerapatan Adat, yang terdiri atas beberapa kepala suku, tabakas Lewu dibantu oleh Damang. Tempat musyawarah dan upacara adat dinamakan Balai Basarah..

Suku Dohoi sangat menghormati dan menghargai para tetua yang mereka sebut dengan bue, mina mama. Segala sesuatu masalah yang timbul, harus didengar pendapat bue dan mina mama.

${ }^{18}$ wawancara dengan Ibu Powili, Warga Dohoi Desa Tukan Kec.Petak Malai, tanggal 
Umum tata karma social ini diatur dalam Kitab Panaturan yang diolah oleh Drs.Rangkap I.Nau dan disahkan oleh Majelis Besar Agama Hindu Kaharingan Pusat Palangkaraya dan di belah menjadi Hukum Adat Dayak Kalimantan Tengah yang meliputi masalah Duniawi meliputi 1. Sahiring, 2. Bali Belum, 3. Biat berarti luka, 4 .Kahasu, 5. Sala Hadat, 6.S aala Basa, 7. Perzinahan 8. Tungkun 9. Perkosaan 10. Penghinaan dan lain sebagainya. Selanjutnya ada hukum Tersilah kepada Agama yaitu perbuatan yang menghina dan mencemarkan hal-hal yang berhubungan dengan kepercayaan masyarakat, misalnya merusak kubur, merusak pahewan, merusak petak rutas, merusak petak pali, merusak indus, merusak sanding, malanggar adat pali disaat kampong memegang rutas, malanggar adat kampong ketika mamapas pali, malanggar adat pali di tempat orang melahirkan dan disaat pengobatan orang sakit,merusak pangantoho, berzinah dengan saudara, berzibah dengan ibu atau bapak, berjinah dengan besan dan merusak pantar.Ancaman hukumannya adalah denda yang digunakan untuk mamapas lewu agarterhindar dari kutukan Ranying Hatalla.

Hukum adat ini terbagi dalam, 1. Papas dakwa 2.Hukum Tarabang dan 3.Tindakan Singer yang memiliki 96 pasal. 19

\section{REPRESENTASI KEPERCAYAAN SUKU DOHOI DALAM BAHASA DOHOI}

Suku Dohoi memiliki kemampuan berbahasa yaitu berbahasa seharihari disebut bahasa Dohi dan bahasa Sangiang disebut Kandaan. Bahasa Kandaan hanya dikuasai oleh para Basir dan pemimpin peribadatan saja. Dalam mengamalkan ajaran agamanya warga Dohoi telah berpedoman pada bahan/kitab ajaran yang sudah dibakukan dalam Panaturan dan Kandayu. Panaturan dan Kandayu berbahasa Ngaju, maka tidak bisa dipungkiri doa dan harapan mereka diucapkan dengan bahasa Ngaju meskipun masih bercampur dengan bahasa Dohoi, seperti yang diungkapkan oleh adik Pitri Elvi Natalia, anak Ibu Pawili menyampaikan doa-doa kegiatan sehari-hari seperti di bawah ini:

a. Doa sebelum makan

Ranying Hatalla Langit, tuh iko esum hong pantai danum kalunen, monahorep rangkan ponginon simpun, iran sako nyatan sukup,mangat hajamban rangkan ponginan simpan tuh, mujan akan ikom Sasangga Tatamba area, Sampar Saribu Sasabutan Biti.Uka rangka ponginan Simpan tuh, tau akan manjadi akan karigas kaabas, ikom halajur, sampai katahitahi . Sahiiyy-Sahiiyy sahiyy (Tuhan Hatalla Langit, ini aku cucumu, di

\footnotetext{
${ }^{19}$ Manli, Hukum Adat Kaharingan (Kapuas: Pemda Kabupaten Kapuas, 2005).
} 
dunia manusia, mengharap terimakasih atas makanan yang Kau berikan sehingga aku kenyang) ${ }^{20}$

Doa sebelum makan menurut Jefri, 15 Tahun asal Desa Tumbang Tangoi sekolah di SMPN-1 Tumbang Samba, nama orang tua Nahan (24 Juli 2017) Uu Tuhan Ranying Hatalla, Iko ucapkan terimo kasih, hondau tuh bai iko nonga ku kare kanah bari jo mamih. Hondau tuh bai aku ri kodan ba doa okam Tuhan. Iko ocap terima kasih umba Iko Ranying Hatalla untuk hondo turi Ranying Hotalla.

(Doa ini diajarkan oleh orang tua kepada Jefri)

b. Doa Sebelum Tidur

Doa sebelum tidur banyak diajarkan oleh orang tua kepada anak-anak mereka. Doa sebelum tidur yang diajarkan oleh Ibu Powili kepada anaknya Pitri Elvi Natalia sebagai berikut

Ranying Hatalla Langit, Jatha Balawang Bulau; Tuh iko Tongang esum hondak nunjong tiruh tingang, mangat Tongang Tatu pahayak iko tingang esumuka tou nopi nekap koyun penyang karuhei tatau, Sandik potarung Songkolemu Raja, Koyun sangko tatomba tokalason peres bo ratus nganguronan orea, mongat misik honjewu koreh tou mondinun borigas abas manampo kore gawi gowian, sahiyyy sahiyy sahiyyy

Beda dengan Jefri, dia diajarkan oleh orang tuanya berdoa sebelum tidur oOi Hatalla Langit,iko tiroh, nunjong iko Tuhan tau misik hondau ijo

c. Doa sebelum Melakukan Perjalanan

Ranying Hatalla Langit, Tuh Aku tingang esum hondak malalus tanjung ,mangot tingong totu Ranying Hatalla Langit, Sohur Paropah Holajur mampohoyak manotop mayohurui tanjung mongat salamat sahiyy sahiiy sahiiy (Ibu Powili)

d. Doa membuka ladang

Oooi Ranying Hatalla Langit, Jatha Balawang Bulau, sonan Duwata, iko polus ho himba duan gawi akan kuman, tuh ruku,simpa,manuk,bori hondang, danum kopi pangganti taluh himba jo matoi, sahiiiy sahiiiy sahiiiy

e. Doa Mencari Ikan

Ranying Hatalla Langit, Jatha Balawang Bulau, tuh iko najong mimbit rengge,beje mandup lauk, loku nonga iko sukup kuman belum anak jorian, sahiiy sahiiy sahiiy

${ }^{20}$ Doa ini diperoleh Pitri Elvi Natalia, pada buku Kandayu yang diberikan oleh Damang Juang K.Djakat di Balai Basarah di Tumbang Atei. 


\section{PENUTUP}

Sistem Religi atau kepercayaan Suku Dohoi adalah apa yang mereka yakini sebagai ajaran dan kepercayaan mereka yaitu, mayoritas berkepercayaan Kaharingan atau agama Helu, yang saat ini mereka terintegrasi (bukan berintegrasi, sebab mereka berjuang tidak putusputusnya untuk diakui sebagai sebuah agama yang memiliki legalitas formal.

Kepercayaan kepada Leluhur masih terus mereka yakini, sehingga banyak upacara-upacara Adat yang masih dilakukan hingga saat ini sepeerti Tiwah, Manyanggar, Mamapas Lewu dan lain sebagainya, sebagai presentasai keyakinan mereka terhadap sebuah kekuatan yang mereka yakini dapat melindungi dan memelihara kehidupan mereka. Oleh sebab itu, segala pujipujian dan doa mereka persembahkan kepada Yang Maha Kuat dan Perkasa yaitu Ranying Hatala Langit Tuhan Yang Mama Esa.

Prosesi dan puji-pujian berbentuk doa doa yang mereka lakukan dalam kehidupan mereka sehari-hari, seperti doa beerangkat belerja, membuka lahan, mau makan, mau tidur dan lain sebagainya. Doa dan puji-pujian itu mereka ucapkan dengan bahasa Dohoi meskipun petunjuknya menggunakan bahasa Dayak Ngaju yang ditulis dalam Buku Kandayu..Kandayu adalah buku pedoman persembahyangan yang dibuat oleh alim ulama Dayak Kalimantan Tengah.

Orang Dohoi tidak memiliki tata peribadatan sendiri, mereka menggunakan tata Peribadatan Dayak kaharingan Kalimantan Tengah yang dibuat dalam Bahasa Ngaju. Meskipun demikian, dalam presentasi doa-doa mereka menggunakan bahasa Dohoi dan juga bahasa Ngaju. Karena menurut Pak Juang K.Djakat Kepala Adat Dohoi orang Dohoi paham bahasa Ngaju karena bahasa Ngaju asalnya adalah bahasa Dohoi, dan ini menarik untuk dilacak kebenarannya melalui penelitian lain.

Orang Dohoi meskipun telah memeluk agama lain selain Kaharingan, mereka tetap mengamalkan Tata Acara Agama Kaharingan sebagai budaya Leluhur mereka, ini dibuktikan jika Orang Dohoi melakukan upacara baik kelahiran,perkawinan dan kematian tetap memakai acara adat Kaharingan sebagai pengejawantahan nilai-nilai budaya luhur mereka

\section{DAFTAR PUSTAKA}

Alqadrie, Syarif. "Ethnicity and Social Change in Dayaknese Society of West Kalimantan, Indonesia." PhD Disertasi, Departement of Sociology, University of Kentucky, 1990.

Giles, Judy, and Tim Middleton. Studying Culture: A Practical Introduction. 2 edition. Malden, MA: Wiley-Blackwell, 2008.

Hall, Stuart. Representation : Cultural Representation and Signifying Practises. London: Sage, 1997. 
Liadi, Fimeir. Refresentasi Nilai Suku Dayak Ngaju Dalam Manalatai Lewun Sansana, Banjarmasin. Banjarmasin: Borneo Pustaka, 2010.

Manli. Hukum Adat Kaharingan. Kapuas: Pemda Kabupaten Kapuas, 2005.

Riwut, Tjilik. Kalimantan Memanggil. Jakarta: Endang, 1958.

Seli, Seselia. "Struktur, Fungsi, Dan Nilai Budaya Dalam Cerita Rakyat Dayak Kanayant Kabupaten Pontianak." Thesis Magister, Program Pascasarjana IKIP, 1996.

Syahdan, Syahdan. "Ziarah Perspektif Kajian Budaya (Studi Pada Situs Makam Mbah Priuk Jakarta Utara )." Jurnal Studi Agama dan Masyarakat 13, no. 1 (June 20, 2017): 65-99.

Ukur, Frodlin. Tantang Djawab Suku Dayak. Jakarta: Gunung Mulia, 1971.

Umberan, Musni. Wujud, Arti Dan Fungsi Puncak-Puncak Kebudayaan Lama Dan Asli Di Kalimantan Barat, Pontianak: Proyek Pengkajian Dan Pembinaan Nilai-Nilai Budaya Daerah. Pontianak: Depdikbud Propinsi Kalimantan Barat, 1994.

Z, Roedy Haryo Widjono A. M. Masyarakat Dayak menatap hari esok. Penerbit PT Gramedia Widiasarana Indonesia bekerja sama dengan Lembaga Bina Benua Putji Jaji-LPPS-KWI, 1998. 